\title{
PREVALENCE OF BREASTFEEDING AND FACTORS AFFECT ITS PRACTICE IN WOMEN ATTENDING PRIMARY HEALTH CARE UNITS IN CAIRO
}

\author{
By
Heba Tollah Mostafa Farag, Noura Essam El-Din Mohamed Ammar and Mohamed Yahia El-Awady \\ Family Medicine Department, Faculty of Medicine, Ain Shams University \\ *Corresponding Author: Heba Allah Mostafa Farag, \\ Phone No.: (+2) 01154557152, E-mail: mfbaker59@yahoo.com
}

\begin{abstract}
Background: Breastfeeding is the healthiest way for providing young infants with the nutrients they need.

Objectives: To determine the prevalence of breastfeeding among women attending primary health care units in Cairo and identified factors affecting it.

Subjects and Methods: A cross-sectional study was conducted among 400 mothers attending in two different primary heath care centers El Tagamoa El Khames and El Zawia.

On the other side focus group discussions (FGD) were conducted within the same two primary health care units, they included a total of 33 mothers who participated in four focus group discussion.

Results: An interview questionnaire was done to identify the prevalence and factors affecting breastfeeding. The prevalence of breast feeding was $94.5 \%$ from which more than half of the infants $66.5 \%$ were mixed fed, $28 \%$ were exclusively breastfed, and only $5.5 \%$ of the infants were not breastfed. There were many factors that negatively affected breastfeeding and had a significant importance in this study including father's educational level, family income, maternal knowledge about importance of breastfeeding, health education about breast feeding in the hospital and time of breastfeeding initiation within 1- 24 hours after birth. Focus group discussions were done to detect farther factors which affect breastfeeding which include: Mother's belief that her milk was not enough, nipple abrasions and ulcers. Maternal employment act as barrier to breastfeeding was also stated.
\end{abstract}

Conclusion: Many factors affected breastfeeding especially maternal employment which plays a major role in breastfeeding continuation or cessation.

Keywords: Breastfeeding, Socio-Demographic Factors, Maternal knowledge, Father Work, Health education.

\section{INTRODUCTION}

Breast milk is the ideal nutrition created for the infant (Wu et al., 2018). It is the best gift a mother can give for her child. It is an important public health strategy for reducing infant and child morbidity and mortality (Woldie et al.,
2014). The World Health Organization (WHO) and UNICEF recommend that children should be exclusively breastfed during the first 6 months of life (WHO, 2010).

Breastfeeding is one of the most important determinants of child survival, 
birth spacing, and the prevention of childhood infections (Gihan et al., 2014). It is a complete food available at no cost and an effective way to provide infant protection in a caring environment (Veerbhan et al., 2013). In developing country more than 800,000 child deaths a year could be prevented by breastfeeding, according to a new report released by UNICEF child protection unit in developing countries, poorer mothers tend to breastfeed longer than others (Setegn et $a l ., 2012)$. In addition, breastfeeding has declined worldwide in recent years, due to urbanization and maternal employment outside the home, early initiation of breastfeeding is not seen in over $75 \%$ of the children and over $50 \%$ of children are not exclusively breastfed (Poreddi et al., 2015).

Many factors affect breastfeeding as maternal age, education, employment, residency, cultural, religious practices, living arrangement, antenatal care practices, home delivery, and professional assistance at birth were found to affect breastfeeding practices. The way the factors influence EBF practice differ from one setting to the other, necessitating the need for setting specific data (Maonga et al., 2016). Besides, mothers believe that her milk is not enough, delicate nipples, lack of adequate draining, nipple chaps and plain nipple are among the problems faced during breastfeeding (Seval et al., 2018). These factors should be recognized in order to support the baby to grow healthy.

\section{Rationale of the study:}

In Egypt, the EDHS (Egypt Demographic and Health Survey, 2014), showed that among infants under two months of age, $71 \%$ received only breast milk. However, the proportion dropped off rapidly. By age 4-5 months, only $13 \%$ of children were exclusively breastfed.

There are gaps in understanding how socioeconomic factors in Egypt affect breastfeeding pattern. Therefore, exploring these factors can help promote breastfeeding and hence decrease infant morbidity and mortality.

\section{Research Hypothesis:}

The prevalence of exclusive breastfeeding is low among women attending primary health care units in Cairo.

\section{Research questions:}

1. What is the prevalence of breastfeeding among mothers attending El Tagamoa El Khames and El Zawia primary health care centers (PHC)?

2. What are the factors that affect breastfeeding among mothers attending El-Tagamoa El-Khames and El-Zawia primary health care centers?

\section{The present work aimed:}

1. To determine prevalence of breastfeeding among mothers attending El Tagamoa El Khames and El Zawia primary health care centers.

2. To determine factors that may affect breastfeeding practice among mothers attending El Tagamoa El Khames and El Zawia primary health care centers. These factors as socioeconomic factors, maternal age, parity, health education 
of mothers about breastfeeding and antenatal care.

\section{SUBJECTS AND METHODS}

Study type: cross sectional study.

Study setting: This study was conducted in two different primary heath care centers EL Tagamoa El khames which is a newly established primary health care center and El Zawia which is an old established one.

\section{Study design:}

- A cross -sectional study was applied in this study to determine prevalence of breastfeeding and factors that may affect it.

- Focus group discussions to identify hidden factors affecting breastfeeding.

\section{Study time:}

The study started in April 2019 and continued till October 2019. The first participant was asked in 12/04/2019 and the last one included in the study was in 08/10/2019.

\section{Sample size:}

Assuming prevalence of exclusive breastfeeding for the first six months is $40 \% \pm 5$ at $95 \%$ confidence interval (EDHS, 2014). A sample size of at least 370 will be enough using EpiInfo 7 program. To avoid any incomplete data a sample of 400 will be recruited, 200 from each primary health care center.

EL-Tagamoa El-khames primary health care center and El Zawia primary health care center were selected based 'on convenience basis.

- The centers were visited three days per week selected by random sampling (Monday-Tuesday-Thursday) to cover all targets age groups according to the immunization schedule.

- Systematic random sample was drawn from the compulsory vaccination session list.

\section{Inclusion Criteria:}

All mothers with infants aged between 6-12 months. The six months age was selected to determine if the infant was exclusively breastfed, whereas one year was selected to avoid recall bias.

\section{Exclusion Criteria:}

i. Preterm infant.

ii. Infants with congenital disease that prevents them from breastfeeding as cleft palate or cleft lip.

iii. Mothers with any disease that prevent her from breastfeeding as Cancer breast, HIV and mother that are exposed to radio or chemotherapy.

\section{Data collection tools:}

\section{An interviewing questionnaire:}

It was adapted from questionnaires used in previous studies (Ghwass and Ahmed, 2011 , Hadeel, 2014), and (Emmanuel Clow, 2017) after being modified by the research team.

- The developed questionnaire was translated into Arabic and a pilot study was done to assess validity, acceptability and comprehension of the questionnaire and necessary requirements were done.

- This questionnaire classified breastfeeding according to the mode of feeding in the first six months into Exclusive breastfeeding, mixed feeding and artificial feeding. 


\section{The questionnaire included five parts:}

i. Socio-demographic data including.

ii. Basic information about the infant including.

iii. Back ground, knowledge evaluation of mother about breastfeeding \& artificial.

iv. Antenatal care received by the mother during pregnancy.

v. Infant feeding information.

\section{Focus group discussions:}

- Focus group discussions (FGD) were conducted with in two primary health care units of Cairo region which are ElTagmoa El-Khames primary health care center and El-Zawia primary health care center. Mothers of infants aged 6-12 months were invited to participate.

- They included a total of 33 mothers who participated in four focus group discussion.

- They included questions about the concept of proper infant nutrition, signs of a hunger and satiety of infant, reasons to introduce other nutrients rather than breastfeeding in the first 6 month of infants and factors which helped the mother to continue exclusive breastfeeding.

\section{Data analysis:}

Following data collection, they were entered using Portable SPSS version 18 (Statistical Package for the Social Sciences; SPSS Inc., Chicago, IL, USA) and suitable statistical tests were applied.
- Description of quantitative variables in the form of mean, standard deviation and range.

- Description of qualitative variables in the form of number and percentage.

- For Quantitative data: Comparison between groups was done by t-test for Independent samples.

- For Qualitative data: Comparison between groups was done using Chisquare test.

- A $\mathrm{p}$ value $\leq 0.05$ was chosen as a level of significance throughout the study. (SPSS)

A thematic analysis was performed to the focus group discussion (FGDs) using the following steps:

- The first step was transcription and translation of the data whereby the FGDs to English by the facilitator. All the transcribed FGDs were read by two authors who did the data analysis.

- The next step was searching for themes.

\section{Ethical considerations:}

- Research ethics committee approval in the Faculty of Medicine was obtained.

- Administration approval from the Ministry Of Health was obtained.

- Informed consents from mothers who participated in the study were obtained.

- Administrative approval from primary health care. 


\section{RESULTS}

The current study included 400 mothers attending vaccination sessions in two primary health care units in Cairo. The prevalence of breast feeding was 94.5\% (378/400) from which more than half of the infants $66.5 \%$ were mixed fed, $28 \%$ were exclusively breastfed, and only $5.5 \%$ of the infants were not breastfed.

The age of participants ranged between 18-42 years with a mean 29 years, \pm SD 4.43. Most of the participants $(49.5 \%)$ received University education, $66.25 \%$ were housewives. The income of the families ranged between 400-22,000 L.E. with a mean 4050 L.E. \pm SD 3826.

The age of the studied mothers, education, and occupation didn't significantly affect breastfeeding in this study. On the other hand there was a statistically significant relation between breastfeeding and participants monthly income. There was a statistically significant difference between breast feeding levels among different health care units. There was a statistically significant relation between breastfeeding and the level of father education (Table 1).

Table (1): Relation between type of feeding and socio-demographic data

\begin{tabular}{|c|c|c|c|c|c|c|c|c|c|}
\hline \multirow{2}{*}{\multicolumn{2}{|c|}{ Parameters $_{\text {Groups }}^{\text {Garas }}$}} & \multicolumn{2}{|c|}{$\begin{array}{c}\text { Exclusive } \\
\text { Breastfeeding }\end{array}$} & \multicolumn{2}{|c|}{ Mixed feeding } & \multicolumn{2}{|c|}{ Non breastfeeding } & \multirow[t]{2}{*}{$\mathbf{F}^{*}$} & \multirow[t]{2}{*}{ P value } \\
\hline & & Mean & SD & Mean & SD & Mean & SD & & \\
\hline \multirow{2}{*}{\multicolumn{2}{|c|}{ Age (years) }} & 29.4 & 4 & 28.9 & 4.5 & 29.2 & 5.4 & 0.59 & 0.56 \\
\hline & & Median & IQR & Median & IQR & Median & IQR & \multicolumn{2}{|c|}{$\mathbf{X}^{2 * * *} \mathbf{P}$ value } \\
\hline \multicolumn{2}{|c|}{ Monthly income (LE) } & 3000 & $\begin{array}{l}1450- \\
4000\end{array}$ & 3000 & $\begin{array}{l}1500- \\
5000\end{array}$ & 4000 & $\begin{array}{l}3000- \\
8000\end{array}$ & 10.73 & $0.01^{\#}$ \\
\hline & & $\mathbf{N}$ & $\%$ & $\mathbf{N}$ & $\%$ & $\mathbf{N}$ & $\%$ & $\mathbf{X}^{2^{* *}}$ & P value \\
\hline \multirow{2}{*}{$\begin{array}{c}\text { Primary } \\
\text { Health Care }\end{array}$} & Elzawia & 73 & $65.2 \%$ & 163 & $61.3 \%$ & 8 & $36.4 \%$ & \multirow{2}{*}{6.44} & \multirow{2}{*}{0.04} \\
\hline & Eltagammoa & 39 & $34.8 \%$ & 103 & $38.7 \%$ & 14 & $63.6 \%$ & & \\
\hline \multirow{4}{*}{$\begin{array}{c}\text { Mother } \\
\text { education }\end{array}$} & Illiterate & 8 & $7.1 \%$ & 11 & $4.1 \%$ & 3 & $13.6 \%$ & \multirow{4}{*}{12.10} & \multirow{4}{*}{0.06} \\
\hline & $\begin{array}{l}\text { Primary } \\
\text { /prep }\end{array}$ & 12 & $10.7 \%$ & 41 & $15.4 \%$ & 0 & $0 \%$ & & \\
\hline & Secondary & 43 & $38.4 \%$ & 76 & $28.6 \%$ & 8 & $36.4 \%$ & & \\
\hline & University & 49 & $43.8 \%$ & 138 & $51.9 \%$ & 11 & $50 \%$ & & \\
\hline \multirow{2}{*}{$\begin{array}{c}\text { Mother } \\
\text { employment }\end{array}$} & Employed & 30 & $26.8 \%$ & 98 & $36.8 \%$ & 7 & $31.8 \%$ & \multirow{2}{*}{3.60} & \multirow{2}{*}{0.17} \\
\hline & House wife & 82 & $73.2 \%$ & 168 & $63.2 \%$ & 15 & $68.2 \%$ & & \\
\hline \multirow{4}{*}{$\begin{array}{c}\text { Father } \\
\text { education }\end{array}$} & Illiterate & 5 & $4.5 \%$ & 10 & $3.8 \%$ & 2 & $9.1 \%$ & \multirow{4}{*}{14.80} & \multirow{4}{*}{0.02} \\
\hline & Primary/Prep & 8 & $7.1 \%$ & 34 & $12.8 \%$ & 0 & $0 \%$ & & \\
\hline & \begin{tabular}{|l|} 
Secondary \\
\end{tabular} & 55 & $49.1 \%$ & 90 & $33.8 \%$ & 6 & $27.3 \%$ & & \\
\hline & University & 44 & $39.3 \%$ & 132 & $49.6 \%$ & 14 & $63.6 \%$ & & \\
\hline
\end{tabular}

*One Way ANOVA test, $* *$ Chi square test, *** Kruskal Wallis test, (FE: Fisher Exact)

\# post hoc test shows significant difference between: Exclusive BF vs non breastfeeding, Mixed feeding vs non breastfeeding.

The number of ante natal care visits ranged between 1-12 visits, with the mean of 10 visits, SD 3.4. Most of participating mothers $(80 \%)$ were multipara and $82.5 \%$ delivered by cesarean section. Only $5.5 \%$ of mothers initiate breastfeeding within the first hour of delivery and $85 \%$ of mothers who delivered in hospital were received formula milk. There was an insignificant relation between participants as regards number of antenatal care, parity and mode of delivery, while there was a statistically significant relation between time of initiation of breastfeeding and infant feeding pattern (Table 2). 
Table (2): Relation between type of feeding and obstetric history

\begin{tabular}{|c|c|c|c|c|c|c|c|c|c|}
\hline \multirow{2}{*}{\multicolumn{2}{|c|}{$\underbrace{\text { Groups }}_{\text {Parameters }}$}} & \multicolumn{2}{|c|}{ Exclusive BF } & \multicolumn{2}{|c|}{ Mixed feeding } & \multicolumn{2}{|c|}{ No breastfeeding } & \multirow[b]{2}{*}{$\mathbf{X}^{2 *}$} & \multirow[b]{2}{*}{ P value } \\
\hline & & Median & IQR & Median & IQR & Median & IQR & & \\
\hline \multirow{2}{*}{\multicolumn{2}{|c|}{ Number of ANC visits }} & 9 & $9-12$ & 9 & $8-12$ & 9 & $9-14$ & 1.39 & 0.50 \\
\hline & & $\mathbf{N}$ & $\%$ & $\mathbf{N}$ & $\%$ & $\mathbf{N}$ & $\%$ & $\mathbf{X}^{2^{* *}}$ & P value \\
\hline \multirow{2}{*}{$\begin{array}{l}\text { Nipple care } \\
\text { during } \\
\text { pregnancy }\end{array}$} & Yes & 100 & $90.1 \%$ & 224 & $86.5 \%$ & 18 & $85.7 \%$ & \multirow{2}{*}{0.98} & \multirow{2}{*}{0.61} \\
\hline & No & 11 & $9.9 \%$ & 35 & $13.5 \%$ & 3 & $14.3 \%$ & & \\
\hline \multirow{2}{*}{ Parity } & Primipara & 17 & $15.2 \%$ & 58 & $21.8 \%$ & 5 & $22.7 \%$ & \multirow{2}{*}{2.27} & \multirow{2}{*}{0.32} \\
\hline & Multipara & 95 & $84.8 \%$ & 208 & $78.2 \%$ & 17 & $77.3 \%$ & & \\
\hline \multirow{2}{*}{$\begin{array}{l}\text { Mode of } \\
\text { delivery }\end{array}$} & CS & 93 & $83 \%$ & 222 & $83.5 \%$ & 15 & $68.2 \%$ & \multirow{2}{*}{3.32} & \multirow{2}{*}{0.19} \\
\hline & Vaginal & 19 & $17 \%$ & 44 & $16.5 \%$ & 7 & $31.8 \%$ & & \\
\hline \multirow{3}{*}{$\begin{array}{c}\text { Pregnancy } \\
\text { duration }\end{array}$} & \begin{tabular}{|l|}
$<37$ weeks \\
\end{tabular} & 11 & $9.8 \%$ & 18 & $6.8 \%$ & 1 & $4.5 \%$ & \multirow{3}{*}{$\begin{array}{c}2.11 \\
\mathrm{FE}\end{array}$} & \multirow{3}{*}{0.67} \\
\hline & \begin{tabular}{|l|}
$37-42$ weeks \\
\end{tabular} & 96 & $85.7 \%$ & 240 & $90.2 \%$ & 21 & $95.5 \%$ & & \\
\hline & $>42$ weeks & 5 & $4.5 \%$ & 8 & $3 \%$ & 0 & $0 \%$ & & \\
\hline \multirow{3}{*}{$\begin{array}{l}\text { Place of } \\
\text { delivery }\end{array}$} & Home & 2 & $1.8 \%$ & 4 & $1.5 \%$ & 0 & $0 \%$ & \multirow{3}{*}{$\begin{array}{c}0.76 \\
\text { FE }\end{array}$} & \multirow{3}{*}{0.95} \\
\hline & Hospital & 104 & $93.7 \%$ & 249 & $93.6 \%$ & 22 & $100 \%$ & & \\
\hline & $\begin{array}{c}\text { Private } \\
\text { clinic }\end{array}$ & 5 & $4.5 \%$ & 13 & $4.9 \%$ & 0 & $0 \%$ & & \\
\hline \multirow{2}{*}{$\begin{array}{l}\text { Number of } \\
\text { born babies }\end{array}$} & Single & 111 & $99.1 \%$ & 265 & $99.6 \%$ & 22 & $100 \%$ & \multirow{2}{*}{$\begin{array}{l}1.50 \\
\mathrm{FE}\end{array}$} & \multirow{2}{*}{0.56} \\
\hline & Triple & 1 & $0.9 \%$ & 1 & $0.4 \%$ & 0 & $0 \%$ & & \\
\hline \multirow{4}{*}{$\begin{array}{l}\text { Time of first } \\
\text { feed for baby }\end{array}$} & $\begin{array}{c}\text { Don't } \\
\text { remember }\end{array}$ & 5 & $4.5 \%$ & 6 & $2.3 \%$ & 0 & $0 \%$ & \multirow{4}{*}{16.407} & \multirow{4}{*}{0.0117} \\
\hline & $<1$ hour & 7 & $6.3 \%$ & 14 & $5.3 \%$ & 1 & $4.5 \%$ & & \\
\hline & 1-24 hours & 95 & $84.7 \%$ & 228 & $85.6 \%$ & 15 & $68.2 \%$ & & \\
\hline & $>24$ hours & 5 & $4.5 \%$ & 18 & $6.8 \%$ & 6 & $27.3 \%$ & & \\
\hline \multirow{2}{*}{$\begin{array}{l}\text { Formula milk } \\
\text { from hospital }\end{array}$} & Yes & 95 & $88.0 \%$ & 210 & $82.4 \%$ & 17 & $77.3 \%$ & \multirow{2}{*}{2.44} & \multirow{2}{*}{0.30} \\
\hline & No & 13 & $12.0 \%$ & 35 & $14.2 \%$ & 5 & $22.7 \%$ & & \\
\hline
\end{tabular}

*Kruskal Wallis test, **Chi square test, (FE: Fisher Exact)

The majority of mothers $76 \%$ received health education during ante natal care visits. At the same time this information was useless $(67 \%)$, while $63.8 \%$ received health education about breastfeeding after delivery there was only a statistically significant relation between hospital health education about importance of breast feeding and type of infant feeding (Table 3).

Table (3): Relation between type of feeding and maternal information received,

\begin{tabular}{|c|c|c|c|c|c|c|c|c|c|}
\hline \multirow{2}{*}{\multicolumn{2}{|c|}{\begin{tabular}{|c|} 
Groups \\
Parameters
\end{tabular}}} & \multicolumn{2}{|c|}{ Exclusive BF } & \multicolumn{2}{|c|}{ Mixed feeding } & \multicolumn{2}{|c|}{ No breastfeeding } & \multirow{2}{*}{$\mathbf{X}^{2^{*}}$} & \multirow{2}{*}{$P$ value } \\
\hline & & $\mathbf{N}$ & $\%$ & $\mathbf{N}$ & $\%$ & $\mathbf{N}$ & $\%$ & & \\
\hline \multirow{2}{*}{$\begin{array}{l}\text { Health education } \\
\text { about breast } \\
\text { feeding in Anti } \\
\text { natal care }\end{array}$} & Yes & 86 & $76.8 \%$ & 202 & $75.9 \%$ & 18 & $81.8 \%$ & \multirow[b]{2}{*}{0.40} & \multirow[b]{2}{*}{0.82} \\
\hline & No & 26 & $23.2 \%$ & 64 & $24.1 \%$ & 4 & $18.2 \%$ & & \\
\hline \multirow{2}{*}{$\begin{array}{l}\text { Value of this } \\
\text { information }\end{array}$} & Useful & 30 & $32.6 \%$ & 64 & $30.9 \%$ & 6 & $33.3 \%$ & \multirow{2}{*}{0.0038} & \multirow{2}{*}{0.998} \\
\hline & Not useful & 62 & $67.4 \%$ & 132 & $69.1 \%$ & 12 & $66.7 \%$ & & \\
\hline \multirow{2}{*}{$\begin{array}{c}\text { HE about breast } \\
\text { feeding in } \\
\text { hospital }\end{array}$} & Yes & 76 & $70.4 \%$ & 158 & $61.5 \%$ & 21 & $95.5 \%$ & \multirow[t]{2}{*}{11.75} & \multirow{2}{*}{0.003} \\
\hline & No & 32 & $29.6 \%$ & 99 & $38.5 \%$ & 1 & $4.5 \%$ & & \\
\hline
\end{tabular}

*Chi square test, (FE: Fisher Exact) 
The maternal knowledge score ranged between 0-8, more than half of participating mothers agree that breast milk is more suitable and healthy for baby it easy to digest and it increased psychological bond between infant and mother. There was a statistically significant relation between breastfeeding pattern and mothers knowledge regarding the value of breast milk to infants (Table 4).

Table (4): Relation between type of feeding and knowledge of mothers about breastfeeding and artificial feeding

\begin{tabular}{|c|c|c|c|c|c|c|c|c|c|}
\hline \multirow{2}{*}{\multicolumn{2}{|c|}{$\mathrm{F}_{\text {Parameters }}^{\text {Groups }}$}} & \multicolumn{2}{|c|}{ Exclusive BF } & \multicolumn{2}{|c|}{ Mixed feeding } & \multicolumn{2}{|c|}{ No breastfeeding } & \multirow{2}{*}{$\mathbf{X}^{2 *}$} & \multirow{2}{*}{$P$ value } \\
\hline & & Median & IQR & Median & IQR & Median & IQR & & \\
\hline \multirow{2}{*}{\multicolumn{2}{|c|}{ Knowledge score (0-8) }} & 8 & $5-8$ & 7 & $5-8$ & 7 & $7-8$ & 11.10 & $0.004^{\#}$ \\
\hline & & $\mathbf{N}$ & $\%$ & $\mathbf{N}$ & $\%$ & $\mathbf{N}$ & $\%$ & $\mathbf{X}^{2^{* *}}$ & P value \\
\hline \multirow{2}{*}{$\begin{array}{c}\text { Breast feeding is } \\
\text { more suitable for } \\
\text { baby }\end{array}$} & Agree & 101 & $90.2 \%$ & 227 & $85.3 \%$ & 22 & $100 \%$ & \multirow{2}{*}{5.01} & \multirow{2}{*}{0.08} \\
\hline & Disagree & 11 & $9.8 \%$ & 39 & $14.7 \%$ & 0 & $0 \%$ & & \\
\hline \multirow{2}{*}{$\begin{array}{l}\text { Breast feeding is } \\
\text { more healthy for } \\
\text { baby }\end{array}$} & Agree & 92 & $82.1 \%$ & 205 & $77.1 \%$ & 22 & $100 \%$ & \multirow{2}{*}{7.17} & \multirow{2}{*}{$\mathbf{0 . 0 3}$} \\
\hline & Disagree & 20 & $17.9 \%$ & 61 & $22.9 \%$ & 0 & $0 \%$ & & \\
\hline \multirow{2}{*}{$\begin{array}{c}\text { Breast milk is easy } \\
\text { to digest }\end{array}$} & Agree & 106 & $94.6 \%$ & 255 & $95.9 \%$ & 22 & $100 \%$ & \multirow{2}{*}{$\begin{array}{c}0.73 \\
\mathrm{FE}\end{array}$} & \multirow{2}{*}{0.68} \\
\hline & Disagree & 6 & $5.4 \%$ & 11 & $4.1 \%$ & 0 & $0 \%$ & & \\
\hline \multirow{2}{*}{$\begin{array}{l}\text { Colostrum rich in } \\
\text { antibodies }\end{array}$} & Agree & 98 & $87.5 \%$ & 228 & $85.7 \%$ & 22 & $100 \%$ & \multirow{2}{*}{3.70} & \multirow{2}{*}{0.16} \\
\hline & Disagree & 14 & $12.5 \%$ & 38 & $14.3 \%$ & 0 & $0 \%$ & & \\
\hline \multirow{2}{*}{$\begin{array}{c}\text { Breast feeding } \\
\text { increase } \\
\text { psychological } \\
\text { bond }\end{array}$} & Agree & 96 & $85.7 \%$ & 230 & $86.5 \%$ & 22 & $100 \%$ & \multirow[t]{2}{*}{3.52} & \multirow[t]{2}{*}{0.17} \\
\hline & Disagree & 16 & $14.3 \%$ & 36 & $13.5 \%$ & 0 & $0 \%$ & & \\
\hline \multirow{2}{*}{$\begin{array}{l}\text { Artificial feeding } \\
\text { decrease mother } \\
\text { bond with baby }\end{array}$} & Agree & 76 & $67.9 \%$ & 171 & $64.3 \%$ & 17 & $77.3 \%$ & \multirow[t]{2}{*}{1.77} & \multirow[t]{2}{*}{0.41} \\
\hline & Disagree & 36 & $32.1 \%$ & 95 & $35.7 \%$ & 5 & $22.7 \%$ & & \\
\hline \multirow{2}{*}{$\begin{array}{l}\text { Baby shouldn't } \\
\text { drink water or } \\
\text { herbs at first } 6 \\
\text { months }\end{array}$} & Agree & 83 & $74.1 \%$ & 165 & $62.0 \%$ & 14 & $63.6 \%$ & \multirow[t]{2}{*}{5.12} & \multirow[t]{2}{*}{0.08} \\
\hline & Disagree & 29 & $25.9 \%$ & 101 & $38.0 \%$ & 8 & $36.4 \%$ & & \\
\hline \multirow{2}{*}{$\begin{array}{l}\text { Baby shouldn't eat } \\
\text { in first } 6 \text { months }\end{array}$} & Agree & 76 & $67.9 \%$ & 164 & $61.7 \%$ & 18 & $81.8 \%$ & \multirow{2}{*}{4.37} & \multirow{2}{*}{0.11} \\
\hline & Disagree & 36 & $32.1 \%$ & 102 & $38.3 \%$ & 4 & $18.2 \%$ & & \\
\hline
\end{tabular}

* Kruskal Wallis test, **Chi square test, (FE: Fisher Exact)

\# post hoc test shows significant difference between: Exclusive BF vs mixed feeding, mixed feeding vs non breastfeeding.

A total of 33 mothers participated in four focus group discussions for detection of hidden factors that affect breastfeeding. The mothers' ages in exclusive feeding focus group discussions ranged between 20 - 31years, with a mean age of 26 years. The majority $(64.7 \%)$ had university education. Almost of them $(88.2 \%)$ were house wives. The mothers' ages in mixed feeding focus group discussions ranged between 22 - 39 years, with a mean age of
29 years. The majority $(68.8 \%)$ had university education and most of them $(62.5 \%)$ are employed.

The focus groups for exclusive breastfeeding showed the majority of mothers in this group continued breastfeeding for 6 months due to benefits to infant health. It made mothers satisfied and increased the bond between the mother and her baby, 5 out of 16 received maternal supports by pediatrician and 
husband, while one out of 16 was the male infant gender. On the other side, the focus groups for mixed feeding showed in the majority of this group barrier to complete breastfeeding which were mostly false ones. Mother's belief that her milk was

\section{DISCUSSION}

This study aimed at the determination of the prevalence of breastfeeding among women attending primary health care units and to identify factors which might affect breastfeeding. Age of participating mothers was between 18-42 years with an average around 29.9.

$49.5 \%$ of participants received university education, whereas $66.25 \%$ were housewives. A similar study in Iran, was carried out and revealed that the mean age of the participants was 26.97 while $23 \%$ of them were university educated, and $90 \%$ of them housewives (Maharlouei et al., 2018). This difference may be due to difference in study type and time.

The prevalence of breast feeding in this study was $94.5 \%$. More than half of the infants $(66.5 \%)$ were mixed fed, $28 \%$ were exclusively breastfed, and only $5.5 \%$ of the infants were not breastfed at all. Our findings were supported by the study done by Shaheen et al. (2018) which revealed the prevalence of EBF is $28.6 \%$, whereas $54.6 \%$ infants received mixed feeding, and only $16.8 \%$ of the infants were not breastfed. EDHS (2014) revealed that $96 \%$ of Egyptian mothers had breastfed in spite of being much less than the result of exclusive breastfeeding which found that about $40 \%$ of children under 6 months were exclusively breastfed, and only $13 \%$ were exclusively breastfed between age 4-5 months. This result might be due to the fact that $80.5 \%$ insufficient occurred in 5 out of 17 due to nipple pain and ulcers. There were also individual reasons as the baby received artificial milk immediately after birth by the hospital and maternal employment barriers.

of mothers in this study received free formula milk from hospital after delivery. This made it easier to utilize this sample and, accordingly, the prevalence of exclusive breastfeeding decline.

The current study revealed that prevalence of breastfeeding initiation within the first hour after labor was $5.5 \%$. This finding approached to wasn't far from Shaheen et al. (2018) who manifested that prevalence of initiation of breastfeeding within the first hour after labor was $2.7 \%$. On contrast, this result was much less than the EDHS (2014) which showed that initiation within the first hour were $27 \%$.

Cesarean section rates in Egypt between 2005 and 2014 increased from $20 \%$ to $52 \%$. At the same period, rates of early initiation of breastfeeding decreased from $40 \%$ in 2005 to $27 \%$ in 2014 . It was expected that the raised rates of cesarean section would continue. In this study, the prevalence of cesarean section was $82.5 \%$. Accordingly, initiation of breastfeeding within the first hour of life was not easy, and mothers could not be expected to do it alone. They required adequate support and guidance on positioning and feeding their infants (WHC,2010).

Many factors affected breastfeeding, and the current study showed that some of these factors had significant relation to breastfeeding, whereas the others were of insignificant importance. The study results showed that family income was 
significantly associated with breastfeeding rates where increased family income was associated with an increase in artificial feeding. These results agreed with that of a study in Quebec, which indicated that annual family income had a negative relationship with breastfeeding and exclusive breastfeeding (Dubois and Giard, 2003). This may be due to the fact that mother's employment had a major role in raising the family income, and also negatively affected breastfeeding.

The study found no statistical significant relationship between parity and breastfeeding. This finding was supported by study which done by Hill et al. (2007) which showed parity was not significantly associated with the continuation of breastfeeding. This might be due to the influence of the mother's awareness and knowledge about breastfeeding importance on breastfeeding initiation and continuation more than the influence of regardless of different ages or parity status.

The current study showed that $47.5 \%$ artificial feeding was more prevalent in fathers who with higher educational level. This finding was in contrast to the study by Mikiel-Kostyra et al. (2005). Who found a statistically significant association between breastfeeding and father's educational level in which low level of fathers' education increased the risk of shorter exclusive breast-feeding It is possible that fathers with higher education had wives of higher education and, therefore, they had jobs which occupied their time and hindered them from breastfeeding.

The current study found that more than $50 \%$ of mothers with higher knowledge about importance of breastfeeding and a positive attitude. However, all mothers who artificially fed their babies agreed that breast feeding was healthier. These results were consistent with previous research that was done in Qatar which found mothers having a high breastfeeding knowledge level did not affect the rate of continued breastfeeding (Nasser et al., 2018). Irrespective of mothers' awareness of the breastfeeding importance, most of them had a misconception that their milk was insufficient to satisfy the infant. These findings were similar to the findings of Zhang et al. (2015) who stated that infants did not receive adequate amounts of breast milk and had a negative effect on breastfeeding decisions.

In the present study, the sex of an infant did not have significant importance with breastfeeding rates. This result was in contrast to a study from Nigeria which showed female infants were more likely to be exclusively breastfeed than male infants (Agho et al., 2011). A study done by Gagnon et al. (2005) revealed that male infants were more likely to be exclusively breastfed than females counter parts. These controversies might be due to difference by socio-cultural factors which led to gender difference in infant feeding practices and indicated a need for better investigating the association.

In focus groups discussion of mothers who exclusively breastfed, the age of mothers was between 20-31 years, while the average age was 26 years. Their majority (64.7\%) had university educational level, and most of them $(88.2 \%)$ were housewives. 
This study found that there were many social cultural factors that affected breastfeeding practices. Breastfeeding created happiness, and of great importance for the baby's growth and immunity.

Black et al. (2013) and Victora et al. (2016) clarified that the infant's digestive system was not well matured, and giving other foods might expose infants to infection. These results enhanced this study that the various advantages related to breastfeeding were based on the mothers, experiences.

Maternal psychological influences of breastfeeding were regarded as one of the exclusive breastfeeding causes in the current study. This result was supported by Krol and Grossmann (2018) who observed that breastfed mothers had reductions in anxiety, negative mood, and stress on compared with formula fed ones.

Maternal support and encouragement were considered as one of the important reasons for exclusive breastfeeding continuation which were supported by Mannion et al. (2013) that women who reported positive support from their partners scored higher breastfed than those reported negative partner support. This might be due to the Egyptian husband who played a major role as a decision maker concerns with the family and household issues which could affect many aspects of family life including infant feeding practices.

On the other side, in mixed feeding focus groups discussions, mother's age was between 22 - 39 with a mean age of 29 years. The majority $(68.8 \%)$ had university education. Nipple pain and ulcers could negatively affect exclusive breastfeeding in the present study which enhanced by a study done in Western Australia which showed that nipple pain was one of the reasons for cessation of breastfeeding (Kent et al., 2015).

In hospitals where formula was used for infant just after delivery led to increase the early breastfeeding cessation in a cohort study which was carried out by Chantry et al. (2014) They showed that in-hospital formula supplementation was associated with decrease breastfeeding. This result enhanced the current study result.

Maternal employment was another cause for early cessation of breastfeeding which appeared in the present study. This result was supported by Hawkins et al. (2007) which found that maternal work could affect breastfeeding initiation and continuation.

\section{CONCLUSION}

Prevalence of exclusive breastfeeding was low among the studied group. There was a significant association between breastfeeding and family income, father's education, maternal knowledge, health education in hospital and time of initiation of breastfeeding. Maternal employment acts as barrier to breastfeeding.

\section{REFERENCES}

1. Agho KE, Dibley MJ and Ogbonmwan S. (2011): Determinants of exclusive breastfeeding in Nigeria. BMC Pregnancy and Childbirth, 11(2):1-8.

2. Black R, Victora C, Walker S, Bhutta Z, Christian P, Onis M, Bhutta ZA, Christian $P$, de Onis $M$, Ezzati M, GranthamMcGregor S, Katz J, Martorell $\mathbf{R}$ and Uauy $R$ (2013): Maternal and child undernutrition and overweight in low-income and middle-income countries. Lancent, 382:427-451. 
3. Chantry CJ, Dewey KG, Peerson JM, Wagner EA and Rivers LA. (2014): InHospital Formula Use Increases Early Breastfeeding Cessation Among First-Time Mothers Intending to Exclusively Breastfeed. Journal of Pediatric, 164(6): 1339-1345.

4. Dubois L and Girard M. (2003): Social determinants of initiation, duration and exclusivity of breastfeeding at the population level: the results of the Longitudinal Study of Child Development in Quebec (ELDEQ 1998-2002). Canadian Journal of Public Health, 94(4):300-305.

5. Egypt Demographic and Health Survey "EDHS" (2014): Nutrition of Children, Youth, and Women. Available at http://www. dhsprogram.com. Date of access : 21-1-2020.

6. Emmanuel $A$ and Clow $S$ (2017): A questionnaire for assessing breastfeeding intentions and practices in Nigeria. BMC Pregnancy Childbirth, 17(1): 174.

7. Gagnon AJ, Leduc $G$ and Waghorn $K$. (2005): In-Hospital Formula Supplementation of Healthy Breastfeeding Newborns. Journal of Human Lactation, 21(4): 397-405.

8. Ghwass A and Ahmed D (2011): Prevalence and Predictors of 6-Month Exclusive Breastfeeding in a Rural Area in Egypt. Breastfeeding Medicine, 6(4):191-196.

9. Gihan F, Ahmad M, May M, Wafaa F and Lobna A (2014): Trends in Breastfeeding and Weaning Practices in Upper Egypt. Medical Journal Cairo University, 82(2): 4552.

10. Hadeel A (2014): Breastfeeding knowledge practice attitudes and influencing factors. Findings from a selected sample of breastfeeding mothers in Bemidji, Minnesota Master Thesis, Minnesota State University Mankato. 2014.

11. Hawkins S, Griffiths LJ, Dezateux $C$ and Law C. (2007): Maternal employment and breast-feeding initiation: Findings from the Millennium Cohort Study. Pediatric and Perinatal Epidemiology, 21(3):242-247.

12. Hill PD, Sharron S, Argubright TM and Aldag JC. (2007): Effects of Parity and
Weaning Practices on Breastfeeding Duration. Public Health Nursing, 14(4):227 234.

13. Kent JC, Ashton E, Hardwick CM, Rowan MK, Chia ES, Fairclough KA, Menon LL, Scott C, Mather-McCaw G, Navarro $K$ and Geddes DT (2015): Nipple pain in breastfeeding mothers: incidence, causes and treatments. International Journal of Environmental Research and Public Health, 12(10): 12247-12263.

14. Krol KM and Grossmann T. (2018): Psychological effect of breastfeeding on children and mother. Bundesgesundheitsblatt Gesundheitsforschung Gesundheitsschutz, 61(8): 977-985.

15. Maharlouei N, Pourhaghighi A, Shahraki HR, Zohoori D and Lankarani KB. (2018): Factors Affecting Exclusive Breastfeeding, Using Adaptive LASSO Regression. International Journal of Community Based Nursing Midwifery, 6(3): 260-271.

16. Mannion CA, Hobbs AJ, McDonald SW and Tough CS. (2013): Maternal perceptions of partner support during breastfeeding. International Breastfeed Journal, 8(4):1-7.

17. Maonga AR, Mahande MJ, Damian DJ and Msuya SE (2016): Factors Affecting Exclusive Breastfeeding among Women in Muheza District Tanga Northeastern Tanzania: A Mixed Method Community Based Study. Maternal and Child Health, 20:77-87.

18. Mikiel-Kostyra K, Mazur J and WojdanGodek E. (2005): Factors affecting exclusive breastfeeding in Poland: cross-sectional survey of population-based samples. Social and Preventive Medicine, 50(1):52-59.

19. Nasser A, Omer F, Al-Lenqawi F, AlAwwa R, Khan T, El-Heneidy A, Kurdi R and Al-Jayyousi G. (2018): Predictors of Continued Breastfeeding at One Year among Women Attending Primary Healthcare Centers in Qatar: A Cross-Sectional Study. Nutrients, 10(8): 1-15.

20. Poreddi V, Tsushee $\mathbf{L}$ and Mythili D. (2015): Knowledge attitudes and breast feeding practices of postnatal mothers. 


\section{HEBA TOLLAH MOSTAFA FARAG et al.,}

International Journal Health Science (Qassim), 9(4):364-374.

21. Setegn T, Belachew T, Gerbaba M Deribe K, Deribew A and Biadgilign S. (2012): Factors associated with exclusive breastfeeding practices among mother singoba district south east Ethiopia. International breastfeeding journal; 7(1):1724.

22. Seval K, Asli $Y$ and Kenan G (2018): Factors Affecting Mothers' Breastfeeding. International Journal of Caring Sciences, 11 (1): 225- 230 .

23. Shaheen HM, Hegazy NN and Sakr SS. (2018): The barriers to breastfeeding among women: a single-center experience. Menoufia Medical Journal, 31(3): 855-861.

24. Veerbhan S, Archana P, Indu M, Ram C, Choudhary R and Sharma BN (2013): The study of socioeconomic factor affecting breast feeding practice among family of rural area of jaipur. International Journal of Medical Science and Education, 1(1):30-39.

25. Victora CG, Bahl R, Barros D, França GV, Horton S, Krasevec J, Murch S, Sankar MJ, Walker N and Rollins NC. (2016): Breastfeeding in the 21st century:
Epidemiology, mechanisms, and lifelong effect. The Lancet, 387(10017): 475-490.

26. Woldie TG, Kassa AW and Edris $M$. (2014): Assessment of exclusive breast feeding practice and associated factors in Mecha district, North West Ethiopia. Science Journal of Public Health, 2(4): 330-336.

27. World Health Organization (2010): Infant and young child feeding. Available At: https://www. who.int/news-room/factsheets/detail/infant-and-young-child-feeding. Date of Access, 9-12-2018.

28. Wu X, Jackson RT, Khan SA, Ahuja J and Pehrsson PR. (2018): Human Milk Nutrient Composition in the United States: Current Knowledge, Challenges, and Research Needs. Currient Development in Nutrtion, 2(7): 1-34.

29. Zhang K, Tang L, Wang H, Binns CW and Lee AH. (2015): Why Do Mothers of Young Infants Choose to Formula Feed in China? Perceptions of Mothers and Hospital Staff. International Journal of Environmental Research of Public Health, 12(5): 4520-4532. 


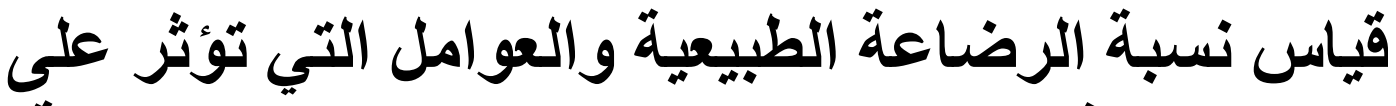

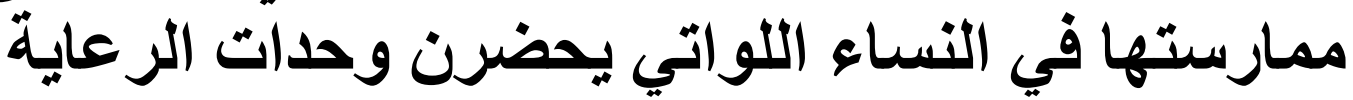 الصحية الأوليةٌ في القاهرة}

هبة الله مصطقى فرج بكر، نورا عصام الدين محمد، محمد يحيى العوضي قسم طب الأسرة، كلية الطب، جامعة عين شمس

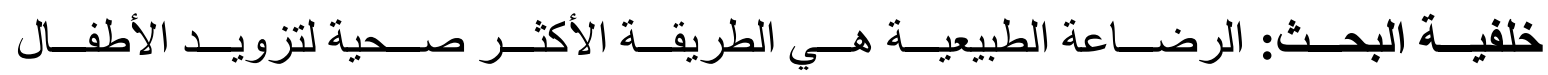
بالمغذيات التي يحتاجون إليها لنمو صحي وسليم.

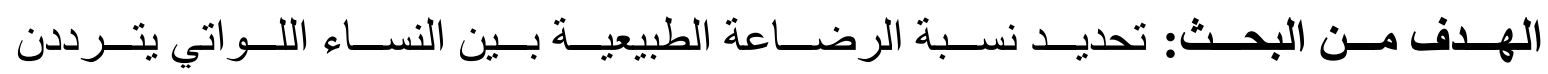

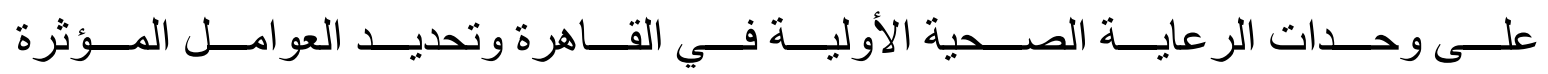
عليها.

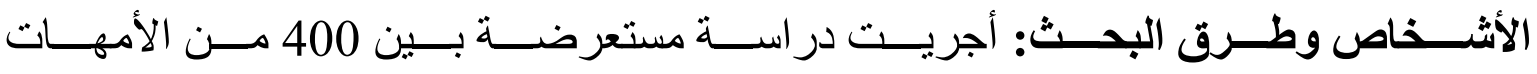

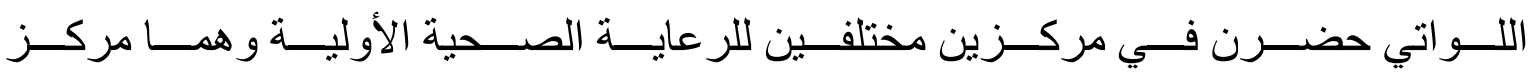
طبي التجمع الخامس ومركز طبي الزاوية.

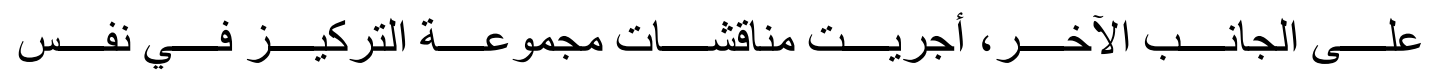

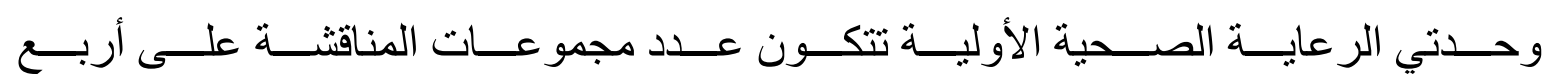
مناقثنات و عدد النساء اللو اتي أنتركن بهم 33 سيدة جماعية مركزة.

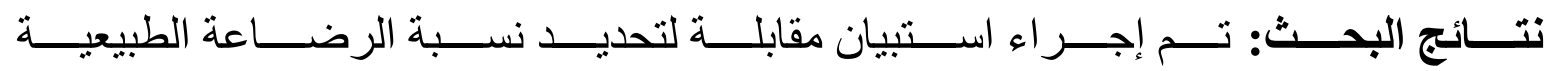

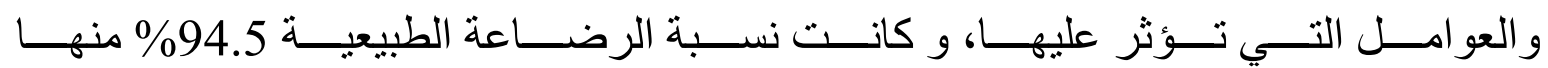

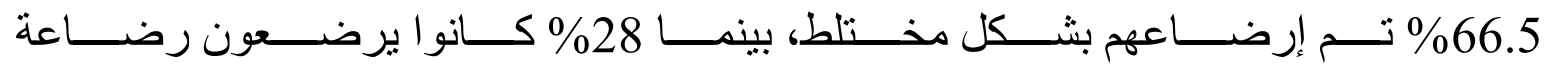

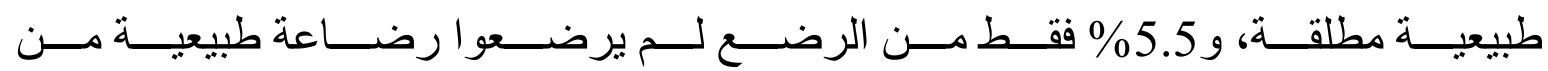

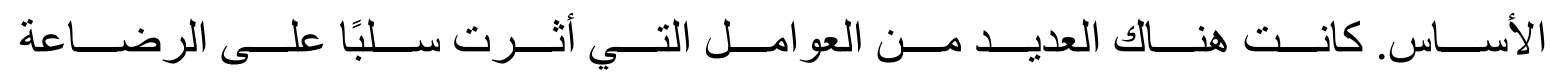

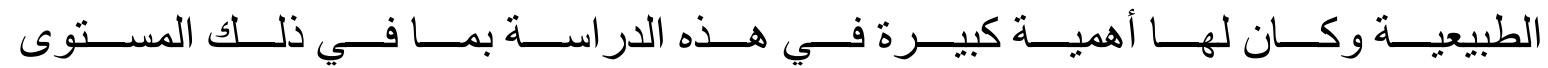

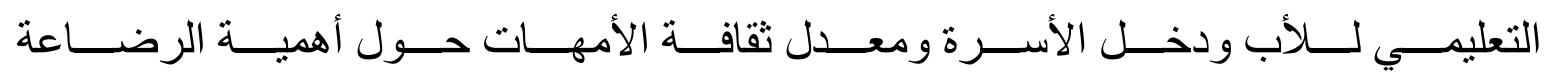




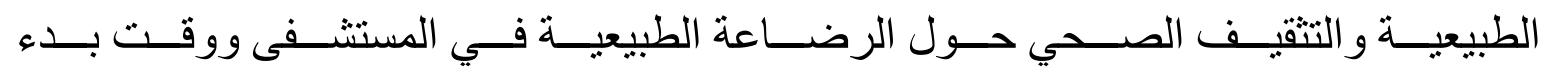
الرضاعة الطبيعية في غضون ساعة إلى 24 ساعة بعد الو لادة.

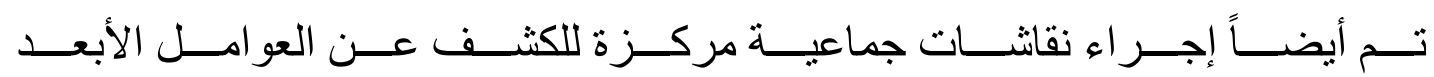

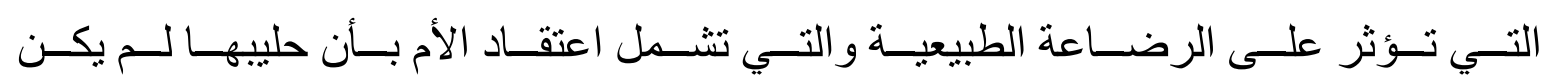

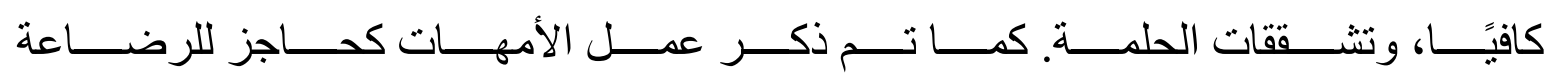
الطبيعية.

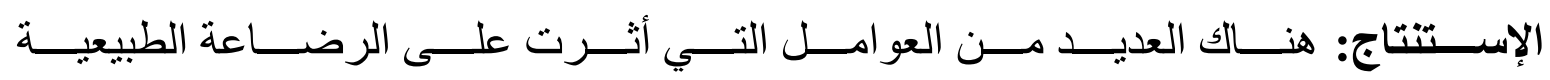

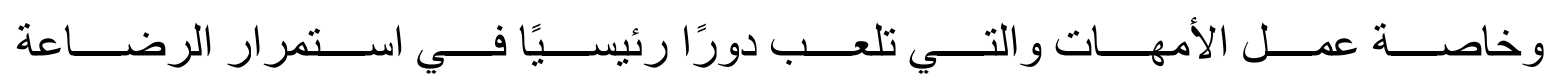
الطبيعية أو التوقف عنها. 